\title{
Detox Instagram Pada Self-Esteem Pengguna
}

\author{
Lisa Harsono, Septia Winduwati \\ lisalilis17@gmail.com,septiaw@fikom.untar.ac.id \\ Fakultas Ilmu Komunikasi Universitas Tarumanagara
}

\begin{abstract}
Instagram is a platform that presents the self-image of someone. When users find out that using Instagram was toxic to their self-esteem, they decided to detox instagram by stopping using Instagram. This research's purpose is to know the self-esteem's user when doing detox Instagram. This research is based on self-concept theory, self-esteem theory, social media theory, Instagram theory, and the detox instagram phenomenon theory. This research is using a qualitative approach with a study case method for college students that stop using Instagram. Collecting data is done by deep interviews. The result in this research shows that when informants doing detox instagram, they appreciate themself, focus on upgrading their potential, and stop comparing their life to each other.
\end{abstract}

Keyword: detox, Instagram, self esteem.

\begin{abstract}
Abstrak
Instagram merupakan platform yang menyajikan citra diri individu. Ketika penggunanya merasakan penggunaan Instagram menjadi toxic bagi self-esteem, maka pengguna memutuskan untuk melakukan deleting toxic (detox) Instagram dengan cara berhenti bermain Instagram. Penelitian ini bertujuan untuk mengetahui self-esteem pengguna ketika melakukan detox Instagram. Penelitian ini berlandaskan pada konsep diri, self-esteem, media sosial, Instagram dan fenomena detox Instagram. Penelitian dilakukan dengan pendekatan kualitatif dengan metode studi kasus pada mahasiswa yang berhenti bermain Instagram. Pengumpulan data dilakukan dengan wawancara mendalam. Hasil dari penelitian ini menunjukkan bahwa ketika informan melakukan detox Instagram, para informan merasa lebih menghargai diri sendiri, fokus kepada potensi yang dimilikinya, dan berhenti membanding-bandingkan diri dengan sesamanya.
\end{abstract}

Kata Kunci: detox, Instagram, self esteem

\section{Pendahuluan}

Dunia maya memungkinkan munculnya cara berkomunikasi baru. Seseorang bisa sangat berbeda kehidupannya antara di dunia nyata dengan dunia maya, terutama di dalam media sosial. Media sosial merupakan alat bantu dalam menyalurkan informasi dari seorang kepada individu atau kelompok orang. Menurut Van Dijk (dalam Nasrullah, 2015), "media sosial adalah platform media yang memfokuskan pada eksistensi pengguna yang memfasilitasi mereka dalam beraktivitas maupun berkolaborasi. Oleh karena itu, media sosial dapat dilihat sebagai medium (fasilitator) online yang menguatkan hubungan antar pengguna sekaligus sebagai sebuah ikatan sosial." Instagram merupakan salah satu media sosial yang paling fenomenal karena media sosial ini berbasis foto dan video. 
Kehadiran Instagram membuat orang ingin memberikan citra yang baik mengenai dirinya. Tanpa disadari, Instagram menjadi candu di mana pengguna terus membagikan foto dan memperlihatkan aktivitasnya kepada followers. Tujuannya agar pengguna mendapatkan pengakuan. Siklus tersebut terjadi terus tanpa henti. Menurut penelitian Royal Society for Public Health di Inggris pada 2017, setelah melakukan survei pada 1.500 remaja di Inggris dengan rentang usia 14 hingga 24 tahun disebutkan bahwa Instagram adalah media sosial terburuk untuk kesehatan mental terutama bagi kalangan anak muda. Jika sang pengguna memiliki self-esteem yang rendah, mereka tidak bisa menyaring konsumsi Instagram dan cenderung membandingkan diri sendiri dengan role model-nya. Lalu menganggap kehidupan orang lain sempurna tidak seperti kehidupannya. Festinger (dalam Armalita, 2018) mengatakan bahwa perbandingan sosial merupakan suatu cara mengukur kemampuan atau kualitas diri seseorang terhadap kualitas diri orang lain, dan adanya perbandingan sosial tidak menyenangkan dikarenakan melihat kehidupan orang lain lebih baik dan sukses dibandingkan diri sendiri menyebabkan munculnya

iri.

Deleting Toxic (Detox) Instagram adalah fenomena orang merasa penggunaan Instagram menjadi negatif bagi dirinya baik secara fisik maupun mental. Pengguna merasa lebih tidak produktif, merasa narsis/minder setelah memakai Instagram, dan lainnya. Fenomena ini dipopulerkan oleh artis-artis baik internasional maupun nasional, yang menghapus Instagram padahal memiliki jumlah followers banyak. Artis yang fenomenal saat menghapus Instagramnya adalah Selena Gomez. Selena menyuarakan efek buruk dari media sosial terutama bagi generasi muda. Selena Gomez memiliki followers terbanyak ketiga di dunia dengan jumlah 152 juta followers dan sempat dijuluki sebagai "ratu Instagram".

Selena mengatakan bahwa konsumsi berlebih pada Instagram sangat mempengaruhi kesehatan mentalnya. Jika melihat orang-orang yang cantik dan luar biasa akan membuatnya kecewa, menilai tubuhnya dengan pandangan yang berbeda, dan membuatnya depresi. Selain itu, banyak waktu dihabiskan Selena di Instagram hanya untuk memperbaiki komentar-komentar orang, sehingga hal-hal tersebut berakibat buruk baginya. Selena memutuskan berhenti menggunakan Instagram sejak 2017. Kini Selena menghapus aplikasi Instagram dari ponselnya. Detox Instagram juga dilakukan oleh orang-orang biasa dan cerita pengalaman mereka dimuat di dalam blogspot atau kompasiana.

Dari latar belakang tersebut, peneliti tertarik meneliti pengguna media sosial yang telah melakukan detox media sosial Instagram. Detox media sosial adalah menarik diri dari aktivitas di media sosial selama suatu jangka waktu lamanya. Rumusan masalah yang terdapat dalam penelitian ini adalah bagaimana self-esteem pengguna setelah melakukan detox instagram? Tujuan penelitian ini adalah untuk mengetahui self-esteem pengguna setelah melakukan detox Instagram.

Menurut Rogers (dalam Kiling, 2015), konsep diri adalah kesadaran yang tetap mengenai pengalaman yang berhubungan dengan individu dan membedakan dirinya menjadi diri yang sebenarnya atau riil dan konsep diri ideal. Konsep diri adalah konsep seseorang dari siapa dan apa itu dia. Konsep merupakan bayangan cermin yang ditentukan sebagian besar dari peran dan hubungan dengan orang lain, serta reaksi orang lain terhadapnya. 
Menurut Pratiwi (2015), self-esteem merupakan rasa nilai diri yang berasal dari perasaan, pikiran, sensasi dan pengalaman sepanjang hidup individu. Setiap individu memerlukan pengetahuan akan self-esteem nya. Self-esteem merupakan keyakinan individu untuk berpikiran dan menghadapi tuntutan hidup, dan keyakinan dalam hak untuk bahagia, perasaan layak, berharga, menilai kebutuhan dan keinginan, dan menikmati hasil dari kerja kerasnya.

Menurut Coopersmith (dalam Aini, 2018), ada dua golongan dalam individu yaitu individu dengan self-esteem yang tinggi dan rendah. Individu dengan selfesteem yang tinggi memiliki sikap aktif dan dapat mengekspresikan diri dengan baik, tidak mudah terpengaruh dari penilaian orang mengenai dirinya, tidak terpaku hanya dari kesulitan yang dihadapinya, mampu menyesuaikan diri dan beradaptasi dengan lingkungan baru, dan lainnya. Sedangkan individu dengan self-esteem yang rendah mempunyai perasaan inferior (merasa diri tidak sempurna), takut akan kegagalan ketika membangun hubungan sosial, sering merasa putus asa dan depresi, merasa terasingkan dan tidak diperhatikan, tidak puas akan dirinya sendiri.

Media sosial merupakan alat bantu dalam menyalurkan informasi dari seorang kepada individu atau kelompok orang. Nasrullah (2016) mengatakan bahwa "media sosial dapat dilihat dari perkembangan bagaimana hubungan individu dengan perangkat media." Salah satu media sosial yaitu Instagram. Kata Insta bersumber dari kata "instan". Arti dari Instagram adalah menampilkan foto secara instan seperti polaroid pada tampilannya. Sementara "gram" bersumber dari kata "telegram" yang berarti mengirimkan informasi secara cepat kepada orang lain. Kesimpulannya Instagram berasal dari kata instan-telegram. Instagram adalah aplikasi media sosial yang menggunakan jejaring internet (Putra, 2019). Instagram merupakan media sosial keempat dengan pengguna terbanyak sebanyak 1 miliar pengguna di dunia. Instagram mempunyai 500 juta pengguna aktif per hari, dan 400 juta pengguna aktif perhari di story Instagram.

Detox berasal dari kata deleting toxic. Toxic berarti racun atau mengandung racun. Instagram merupakan platform untuk membagikan foto dan video ke sesama pengguna. Instagram dapat menjadi platform yang baik jika dipergunakan dengan baik, seperti menjadi platform untuk menghasilkan uang melalui online shop atau endorsement, menjalin hubungan dengan teman lama, keep in touch dengan temanteman yang jauh, dan lain-lain. Namun Instagram dalam kondisi tertentu dapat menjadi toxic jika berakibat buruk kepada penggunanya, seperti menghilangkan harga dan kepercayaan diri dengan membanding-bandingkan diri dengan orang lain, menjadi cemas, susah tidur, depresi, iri dengan kehidupan orang lain, dan lainlain.

\section{Metode Penelitian}

Peneliti menggunakan pendekatan kualitatif. Menurut Ndraha (Kwan, 2019), penelitian kualitatif merupakan penelitian yang bertujuan untuk menemukan pengetahuan seluas-luasnya mengenai suatu objek penelitian pada satu masa atau saat tertentu. Menurut Nasir (Kwan, 2019), metode kualitatif merupakan suatu metode dalam penelitian kelompok manusia atau sekelompok objek, suatu kondisi, suatu sistem pemikiran, atau suatu kelas peristiwa pada masa sekarang. Penelitian 
ini menekankan kepada pemahaman mengenai masalah dalam kehidupan sosial berdasarkan kondisi yang realitas. Tujuan utama penelitian kualitatif adalah memahami fenomena atau gejala sosial dengan memberi penggambaran yang jelas mengenai fenomena atau gejala sosial tersebut dalam bentuk rangkaian kata yang akhirnya akan menghasilkan sebuah teori.

Penelitian ini menggunakan metode penelitian studi kasus. Metode studi kasus adalah metode yang mendalami suatu kasus tertentu dengan melibatkan pengumpulan beraneka sumber informasi. Creswell (dalam Semiawan, 2010) mendefinisikan studi kasus sebagai suatu eksplorasi dari sistem yang terkait (bounded system) atau kasus. Tujuan dari penelitian ini untuk mendapatkan pemahaman mendalam mengenai detox Instagram. Dalam penelitian ini, subjek penelitiannya merupakan mahasiswa yang sudah pernah melakukan detox Instagram selama minimal satu bulan dan obyek penelitian merupakan self-esteem mahasiswa setelah melakukan detox Instagram selama minimal satu bulan.

Teknik pengumpulan data di dalam penelitian ini menggunakan wawancara mendalam, dokumentasi, dan studi kepustakaan. Teknik keabsahan data yang digunakan adalah teknik triangulasi data. Menurut Sugiyono (2013), triangulasi merupakan teknik pengumpulan data yang menggabungkan dari berbagai teknik pengumpulan dan sumber data yang ada. Triangulasi juga menguji kredibilitas data dengan berbagai teknik pengumpulan data dan sumber data.

\section{Hasil Temuan dan Diskusi}

Dari hasil wawancara dengan informan, peneliti menemukan bahwa ketika bermain Instagram, perasaan berharga dapat diperoleh dari karakter masing-masing individu. Bagi informan yang mempunyai karakter yang perfeksionis, informan tersebut mempunyai ekspektasi yang tinggi kepada dirinya dan orang-orang, sehingga ketika ekspektasinya tidak terpenuhi (like dan komen sedikit), ia menjadi kecewa kepada orang-orang dan dirinya sendiri, merasa tidak cukup baik.

Informan lain mempunyai karakter easy going dan tidak mempedulikan timbal balik dari orang lain. Informan jenis ini mengunggah konten hanya untuk kesenangan pribadi, sehingga tidak ada target spesifik yang ingin dicapai. Efeknya, informan dengan karakter yang tidak mempedulikan timbal balik orang cenderung merasa self-esteem mereka rendah ketika melihat kehidupan orang lain. Sebaliknya, informan yang mempunyai karakter sensitif akan merasa tidak puas diri dan tidak tahan akan kritikan berupa komentar teman atas foto yang diunggah. Komentar tersebut hanya candaan namun menyangkut kehidupan pribadinya.

Ketika masih bermain Instagram, ideal self para informan menjadi tinggi karena paparan Instagram. Sebagian besar informan membanding-bandingkan dirinya dengan orang lain. Pada saat yang sama, jurusan di perkuliahan para informan ini mengharuskan mereka banyak belajar, sehingga ketika melihat orang lain bersenang-senang muncul perasaan iri hati dan merasa hidup tidak berarti karena hanya diisi dengan belajar. Informan pengguna ini cenderung menginginkan kehidupan orang lain yang terlihat lebih enak. Sebagian besar informan mengalami self-esteem yang rendah ketika masih menggunakan Instagram. Sementara 
informan lain tidak merasa iri namun kesal dan emosional dengan orang-orang yang memamerkan kehidupannya di Instagram.

Setelah berhenti bermain Instagram, semua informan merasa jauh lebih menerima diri sendiri dengan berhenti membanding-bandingkan, fokus dan mengembangkan diri sendiri. Dapat disimpulkan bahwa para informan memiliki image self dengan ideal self yang dekat karena tidak diberikan paparan kehidupan yang sempurna. Mereka menjadi diri sendiri dan berusaha menjadi versi terbaik dari dirinya. Mereka masih mempunyai ideal self, tetapi ideal self yang memicu mereka untuk bertumbuh.

Ketika berhenti menggunakan Instagram, self-esteem para informan menjadi lebih baik dan individu menyadari keunggulan dalam diri mereka yang disebut dengan domain. Self esteem memiliki ketertarikan yang kuat pada satu domain tertentu terkait persepsi diri. Jadi, domain tersebut dianggap penting oleh individu, sehingga individu akan memiliki self esteem yang tinggi ketika domainnya menjadi baik dan memuaskan. Sebagian informan merasa memiliki domain di bidang penampilan. Mereka menjadi lebih percaya diri dan menerima penampilan mereka yang sekarang, dan mengembangkannya menjadi lebih baik. Informan lain memiliki domain di bidang kepandaian, karena ketika tidak menggunakan Instagram informan dapat melanjutkan untuk menekuni pelajaran. Informan lainnya merasa memiliki domain dalam hal penerimaan diri. Informan mengatakan belum mencapai tahap kepercayaan diri sehingga ia menerima dirinya dan tidak membiarkan diri dijatuhkan oleh orang lain.

Dalam mengembangkan domain dibutuhkan motivasi. Setiap informan mempunyai target yang berbeda. Namun semua informan berpendapat bahwa motivasi dan perasaan mampu datang dari dalam diri. Ketika mereka merasa butuh mengembangkan dirinya, mereka akan mengejar target mereka dengan kemauan sendiri dengan dibantu panduan dari media sosial lain seperti YouTube. Bagi mereka, melihat konten pada Instagram tidak memberi motivasi, malah terkadang melemahkan. Menurut para informan, motivasi harus datang dari dalam diri, karena motivasi yang berasal dari luar diri tidak bertahan lama.

Setelah berhenti menggunakan Instagram, semua informan sudah tidak ingin membagikan prestasi dan kebanggaannya di Instagram. Sebagian besar dari informan mengatakan mereka tidak perlu dilihat oleh banyak orang, cukup bersama teman-teman terdekat ketika memperoleh prestasi. Sementara informan lainnya mengatakan tidak ingin membagikan foto ke Instagram karena terkesan pamer dan apapun yang informan unggah/post akan mendapat kritikan. Informan merasa lebih baik tidak mengunggah foto tersebut. Hal ini diperkuat oleh pernyataan key informan yang mengatakan bahwa anak muda membutuhkan pengakuan. Namun pengakuan dapat diperoleh dengan cara lain seperti mengikuti organisasi, ekstrakurikuler, dan lain-lain. Dari sini dapat disimpulkan bahwa ketika informan sudah merasa puas diri dan memiliki harga diri yang baik maka pengakuan dari lingkungan sosial hanya menjadi tambahan, bukan lagi kebutuhan. 


\section{Simpulan}

Instagram merupakan media sosial yang netral. Namun penggunaan Instagram yang salah berakibat Instagram menjadi toxic. Pengguna yang tidak dapat menyaring konsumsi visual dari Instagram akan cenderung mengalami perubahan self-esteem. Jika individu tidak memiliki pendirian yang kuat maka dapat melemahkan self-esteem individu. Setelah informan menemukan bahwa konsumsi berlebih pada Instagram tersebut toxic bagi hidupnya dan memutuskan untuk berhenti, hasil yang didapatkan adalah mereka menjadi lebih dapat menerima diri sendiri, memiliki pemahaman bahwa manusia tidak ada yang sempurna. Mereka juga memutuskan untuk mengembangkan diri sesuai dengan potensi dan bakat daripada menghabiskan waktu untuk melihat dan iri akan kehidupan orang lain.

\section{Ucapan Terima kasih}

Atas terselesaikannya penelitian ini, peneliti mengucapkan terima kasih kepada orang tua yang memberikan dukungan dan doa, kepada para informan yang meluangkan waktu untuk membantu penelitian ini, dan kepada teman-teman yang telah menemani dan membantu peneliti dalam penyusunan skripsi ini.

\section{Daftar Pustaka}

Nasrullah, Rulli. M.Si., Dr. (2015). Media Sosial : Perspektif Komunikasi, Budaya dan Sosioteknologi. Jakarta : Simbiosa Rekatama Media.

Semiawan, Prof. Dr. Conny R. (2010). Metode Penelitian Kualitatif. Jakarta: Grasindo.

Killing, Beatriks Novianti \& Kiling, Indra Yohanes (2015). Tinjauan Konsep Diri dan Dimensinya Pada Anak Dalam Masa Kanak-Kanak Akhir. Jurnal Psikologi Pendidikan \& Konseling, 1 (2), 116-124.

Kwan, Predik \& Hardianto, Willy Tri \& Setiawan, Dody (2013). Upaya Pemerintah Desa Dalam Meningkatkan Kualitas Pelayanan Pada Masyarakat. Jurnal Ilmu Sosial dan Ilmu Politik, 2 (2).

Putra, Albertus Adi \& Santosa, Adi \& Nilasari, Poppy Firtawentyna. (2019). Kajian Perbandingan Kenyamanan Ruang Desain Interior Kafe yang Instagramable di Surabaya (Studi Kasus: Carpentier Kitchen dan Threelogy Coffee). Jurnal Intra, 7 (2), 933-941.

Aini, Dian Fitri Nur. (2018). Self Esteem Pada Anak Usia Sekolah Dasar untuk Pencegahan Kasus Bullying. Jurnal Pemikiran dan Pengembangan SD, 6 (1), 36-40. http://ejournal.umm.ac.id/index.php/jp2sd/article/view/5901/5442

Anna, Lusia Kus (2017, Juli 14). Instagram, Media Sosial Paling Buruk Bagi Kesehatan Mental. Kompas database. https://lifestyle.kompas.com/read/2017/07/14/073913720/instagram-mediasosial-paling-buruk-bagi-kesehatan-mental?page=all 
Brown, Jessica. (2018, Januari 16). Apa saja Bukti Pengaruh Media Sosial Kehidupan Anda. BBC Indonesia database. https://www.bbc.com/indonesia/vert-fut-42679432

Pratiwi, Wahyuni Eka (2015). Pengaruh Budaya Jawa dan Harga Diri Terhadap Asertivitas Pada Remaja Siswa Kelas XDI SMA Negeri 3 Ponorogo. Jurnal Psikologi, 3 (1), 348-357.http://ejournal.psikologi.fisip-unmul.ac.id/site/wpcontent/uploads/2015/02/JURNAL\%20YUNI\%20(02-18-15-05-23-25).pdf

Putri, Virginia Maulita (2019, Febuari 1). Instagram Stories Punya 500 Juta Pengguna Aktif per Hari. Detik.com database. https://inet.detik.com/cyberlife/d-4410328/instagram-stories-punya-500juta-pengguna-aktif-per-hari

Wiyanti, Widiya. (2019, Juni 20). Demi Kesehatan Mental, Selena Gomez Hapus Instagram dari ponselnya. Detikcom Database. https://health.detik.com/berita-detikhealth/d-4593121/demi-kesehatanmental-selena-gomez-hapus-instagram-dari-ponselnya 